\title{
Upper Gastrointestinal Tract
}

National Cancer Institute

\section{Source}

National Cancer Institute. Upper Gastrointestinal Tract. NCI Thesaurus. Code C33837.

The upper part of the gastrointestinal tract that includes the esophagus, stomach, and duodenum. 